\title{
Percutaneous core biopsy of the penis
}

\author{
Sarwat Hussain ${ }^{1}$, A Nehra², I Goldstein ${ }^{2}$ and R J Krane ${ }^{2}$ \\ Department of ${ }^{1}$ Radiology and ${ }^{2}$ Urology, Boston University Medical Center Hospital, 88 East Newton Street, Boston, \\ MA 02118, USA
}

\begin{abstract}
To describe the efficacy of percutaneous core biopsy of penile corporal tissue, on ten impotent men, the biopsy was performed with a 19 and a 20 gauge core biopsy co-axial system using an automatic biopsy device. All biopsies were performed on an outpatient basis under local anesthesia. Adequate biopsy specimens were obtained in all. Percutaneous core biopsy of the penis is a safe procedure that is technically easy to perform.
\end{abstract}

Keywords: penile biopsy; percutaneous biopsy; core biopsy

\section{Introduction}

Numerous reports have documented that patients with vasculogenic impotence develop corpora cavernosal trabecular structural alternations. ${ }^{1-3}$ Histopathologic and computer-assisted point counting technique with color histomorphometric studies as well as electron microscopic investigations have shown abnormal cavernosal smooth muscle cells with irregular contour of the cell wall, pleomorphic nuclei and sparse glycogen particles, aggregated mitochondria and decreased contractile elements in the cytoplasm. ${ }^{4}$ It has also been reported that the severity of symptoms and clinical findings in impotent men is proportional to the percentage of altered corporal smooth muscle cells. ${ }^{5}$

Currently, sampling of the penile tissue is carried out at the time of penile prosthetic surgery. ${ }^{5}$ Results of the biopsy, therefore can not contribute to the decision making and the treatment planning of impotence. Wespes has described a method of cavernous biopsy in the past. ${ }^{6}$ We describe an improved technique of percutaneous core biopsy of the penis provides the opportunity to sample cavernosal tissue pre-operatively.

\section{Materials and methods}

This project was approved by our Institution Review Board (IRB). A non-selected group of patients who

Correspondence: Prof. S Hussain, MBC 28, King Faisal Specialists Hospital and Research Center, PO Box 3354, Riyadh 11211, Saudi Arabia.

Received 11 February 1997; revised 10 April 1997; accepted 6 May 1997 were undergoing dynamic infusion corpora cavernosography (DICC) for the work-up of impotence were offered biopsy. In ten patients, who agreed to sign the informed consent, biopsy was carried out. Patient's ages varied between 27 and 63 with an average of $51.2 \mathrm{y}$. One patient was diabetic. There was no other significant medical history in any of the patients. In nine patients the biopsy was carried out immediately prior to DICC, in one it was done on a separate day.

\section{Technique}

Local anesthesia, $3 \mathrm{ml}$ was used to anesthetize skin and subcutaneous tissue at the 2 o'clock position along the dorsal surface of the penile shaft immediately proximal to the region of corona of the glans penis.

A coaxial needle biopsy system was utilized. The system consisted of an automatic biopsy device (ABD) and two needles (Manan Medical Products, Northbook, IL); a 19 gauge $(19 \mathrm{G}) 3.8 \mathrm{~cm}$ long thin walled guiding needle through which a 20 gauge $(20 \mathrm{G}) 8 \mathrm{~cm}$ core biopsy needle was placed in the cavernosal tissue for biopsy passes. The length of the needles was such, when the ABD loaded with $20 \mathrm{G}$ needle in cocked position was introduced through $19 \mathrm{G}$ needle the tips of the two needles coincide with each other. As the ABD with $20 \mathrm{G}$ needle the tip traveled for $12 \mathrm{~mm}$ with needle shaft containing an $8 \mathrm{~mm}$ specimen notch.

After placement of the guiding (19G) needle into the cavernosal tissue via the anesthetized area, the glans penis was pulled and held firmly between the thumb and the index finger of the left hand. The trajectory of the $19 \mathrm{G}$ needle was maintained parallel 
to the tunic albuginea along the sagittal plane of the penis. The cocked ABD loaded with $20 \mathrm{G}$ needle was introduced through $19 \mathrm{G}$ needle. A maximum of four specimens were obtained with different lengths of introduction of the guiding needle into the penile tissue. At the end of the procedure, local pressure on the penis was applied for $10 \mathrm{~min}$ and patient discharged home with pressure bandage to the penis.

Possible complications of local pain during biopsy, counter puncture of tunica albuginea or injury to the urethra was recorded. The patient was called on the phone to inquire about any complications the next day and was instructed to report to emergency department if hematoma or any other complications should occur.

The biopsy specimens were fixed in $10 \%$ Formain of Bouin's fluid and allowed to fix overnight at $4{ }^{\circ} \mathrm{C}$. Paraffin tissue blocks were prepared and cut in $3 \mu$ thick sections. Staining was performed for general histological analysis with hematoxylin and eosin or for trabecular smooth muscle (red) and connective tissue (blue) with Masson's trichrome. Using image analysis computer software (optimas 4.0 BioScan) color histomophometric evaluation was done to calculate the percentage of the trabecular smooth muscle to the total erectile tissue. ${ }^{7}$

\section{Results}

Biopsy specimens of cavernosal tissue were considered adequate in all 10 patients by the histopathologists for computer assisted color histomorphometric and immunohistochemical studies. No complications occurred. After the initial local anesthesia, no pain was experienced by any of the patients. No significant hematoma, bleeding or deterioration of erectile function was observed or reported. As this is a report on the technique of percutaneous biopsy of the penis during DICC, no attempt was made to correlate the results of biopsy with other findings in the work up of impotence.

\section{Discussion}

The relationship between the response to the penile vascular reconstructive surgery and the volume percentage of smooth muscle and the fibrous tissue contents of corpora cavernosa has been reported in the recent studies. ${ }^{2,4,5}$ The presence of an excessive amount of fibrous tissue and loss of the smooth muscles seem to be related with reduced chances of surgical success. ${ }^{4,5}$ It has been shown that patients with greater than $29 \%$ smooth muscle cells on cavernous biopsy responded well to penile venous surgery. ${ }^{5}$ Coaxial approach of cavernosal biopsy provides opportunity to obtain several samples with a single puncture of the tunica albuginea. In nine of
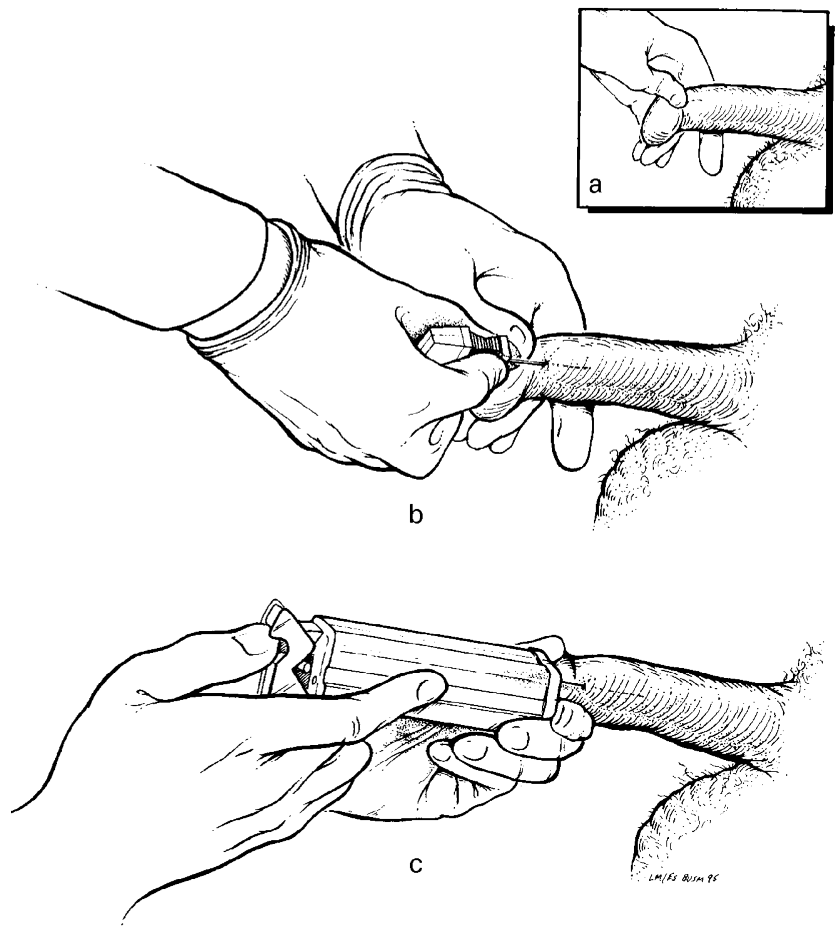

Figure 1 Technique of core biopsy of the penis: (a) The penis is held at the glans and firmly pulled out straight; (b) After infiltration of local anesthesia a guiding $19 \mathrm{G}$ needle is introduced parallel to the outer wall of the tunica albuginea; (c) A $20 \mathrm{G}$ core biopsy needle is now introduced coaxially to obtain cavernosal samples.

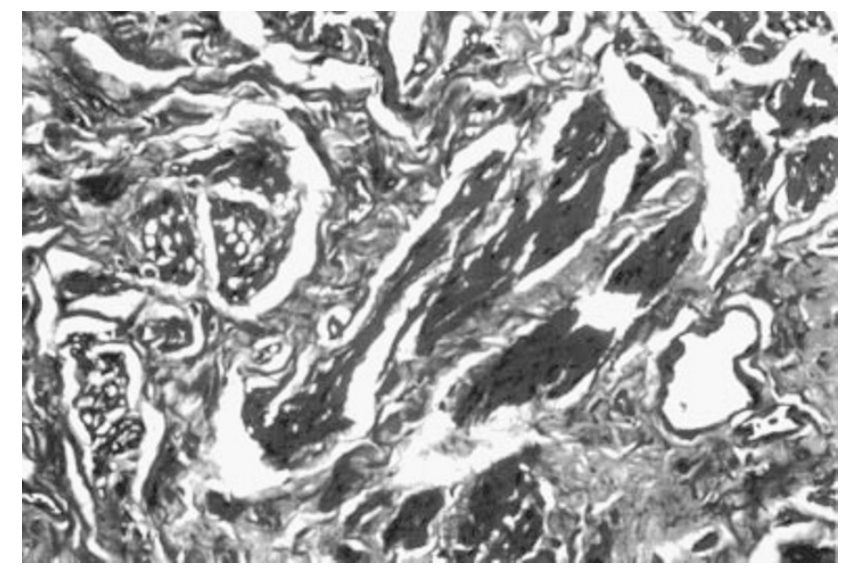

Figure 2 Microphotograph $(\times 400)$ of the histology specimen from core biopsy showing smooth muscles and fibrous tissue after Masson's trichrome stain.

our patients the guiding biopsy needle was left in place for a subsequent diagnostic DICC study.

In cadavers, cavernosal tissue biopsy has been successfully performed using an automatic biopsy device. Wespes et $a l^{6}$ reported biopsy of cavernous body with single pass of a biopsy needle using 'Biopty gun'. ${ }^{6}$ In this report the information is not 
available as to the dimensions of the biopsy needle or whether the biopsy was performed in conjunction with DICC. We describe a technique of core biopsy of the penis that can be combined with DICC so that the need for a second penile puncture can be obviated by leaving the $19 \mathrm{G}$ guiding needle in place for DICC. For a better tissue yield, the biopsy must be performed on a flaccid penis as much of the penile volume in an erect state consists of blood distended cavernosal lacunae. Vascular impotence is a diffuse penile disease. Therefore, cavernosal biopsy from one region of the penis would suffice to study the penile structure in the assessment of vascular impotence. ${ }^{8,9}$ If the smooth muscle to collagen tissue ratio is favorable on core biopsy, it may be possible to avoid surgery and patients managed by non-surgical means. In patients with, say, less than $29 \%$ smooth muscles in penile tissue, penile prosthetic surgery may be seriously considered. Besides, penile biopsy can be used as a research tool to assess the progression or regression of corporal fibrosis in patients after radical prostatectomy.

\section{Conclusions}

Core biopsy of the penis is a safe and substantially painless procedure that can provide clinically
Percutaneous core biopsy of the penis

S Hussain et al

useful information in the work-up of erectile dysfunction and help make management decision particularly prior to penile implants surgery.

\section{References}

1 Goldstein I. Review of types and results of vascular surgical procedures for impotence. Cardiovasc Intervent Radiol 1988; 11: $240-244$.

2 Lewis RW. Venous surgery for impotence. Urol Clin North Am 1988; 15: 115-121.

3 Krane JR, Goldstein I, Saenge Tegada I. Medical progress: impotence. New England J Med 1989; 321: 1648-1659.

4 Presson $\mathrm{C}$ et al. Tanoghoea: Correlation of altered penile ultrastructure with clinical arterial evaluation. J Urol 1989; 142: $1462-1468$.

5 Wespes Goes PM, Sattar AA, Schulman C. Objective criteria in the long-term evaluation of penile venous surgery. J Urol 1994; 152: 888-890.

6 Wespes E, Depierreux M, Schulman CC. Use of biopty gun for cavernous biopsy. Int J Impot Res 1990; 2: 228-229.

7 A. Nehra et al. Mechanism of Venous Leakage: A prospective clinicopathological correlation of corporeal function and structure. J Urol 1996; 156: 1320-1329.

8 Meuleman EJH et al. The role of penile biopsies in the evaluation of erectile dysfunction: a histo-morphometric study of the human cavernous body. Int J Impot Res 1990; 2: 230-231.

9 Wespes E, De Goes PM, Schulman C. Vascular impotence: focal of diffuse penile disease. J Urol 1992; 148: 1435-1436.

\section{Editorial comment}

\section{Percutaneous core biopsy of the penis-by Sarwat Hussain et al}

Hussain et al, in this issue, have provided us with a new variation on the issue of penile biopsy. In their report they show it is possible to obtain cavernous tissue that is adequate for evaluation from the same site as is used for subsequent DICC. Dr E Wespes has been the prime proponent of biopsy since his paper in 1990 documenting the feasibility of core biopsy ${ }^{1}$ and his more recent analysis of biopsies in the mangement of men with veno-occlusive dysfunction. ${ }^{2}$ It is clear that the penis provides the same opportunity for biopsy as it does for local injection: It is accessible and there are few complications.

Penile biopsy and cavernous tissue analysis promises to reveal the functional potential of cavernous tissue by identifying the percentage of fibrous tissue present. High percentages produce stiff cavernous tissue that expands poorly and either never achieves the inflow or the veno-occlusion that is needed for a rigid erection. This concept may be developed into a reliable way of proving that particular penile tissue is damaged beyond salvage so justifying, and documenting that justification, the insertion of a prosthesis or the performance of a venous leak procedure.

Biopsy is a diagnostic test and should be subjected to the same evaluation as all diagnostic tests: Is it safe? Is it reproducable? Does it change management for the better? Is it cost effective? We cannot afford to embrace the new diagnostic tests that have the potential to be applied widely, just because they are simple, before they are independently validated. ${ }^{3}$

The real concern here is that the technique of biopsy is simple but the means of analysis is complex, involving as it does the use of several stains and computer aided image analysis. With the leadership of the authors above, and validated 
through outcome studies where the new information is used prospectively to direct therapy, we may see the introduction of biopsy as a regular component of the management of erectile dysfunction. However, until such time penile biopsy should remain in the hands of experts and in clinical trials and not become part of routine clinical management.

\section{References}

1 Wespes E, Depierreaux, M, Schulman, CC. Use of biopty gun for corpus cavernosum biopsies. Eur Urol 1990; 18: 8.

2 Wespes $\mathrm{E}$ et al. Objective criteria in the long-term evaluation of penile venous surgery. J. Urol 1994; 152: 888-890.

3 Jaeschke R, Guyatt G, Sackett DL. Users' guides to the medical literature. III. How to use an article about a diagnostic test. A. Are the results of the study valid? JAMA 1994; 271 (5): 389-91.

JPW Heaton 